03

\title{
SPATIO-TEMPORAL ANALYSIS OF LAND USE AND LAND COVER IN DELHI-NCR USING SATELLITE DATA
}

\author{
Sant Prasad ${ }^{1 *}$, R. B. Singh ${ }^{2}$ and B. W. Pandey ${ }^{3}$ \\ ${ }^{1}$ Research Scholar, ${ }^{2,3}$ Professor, \\ Department of Geography, Delhi School of Economics, University of Delhi, Delhi, India. \\ Email:rbsgeo@hotmail.com, bwpdsegeo@gmail.com \\ *Corresponding author Email: santprsd1@gmail.com
}

How to cite this paper:

Prasad, Sant; Singh, R.B. and Pandey, B.W. (2021)

Spatio-Temporal Analysis of Land Use and Land Cover in Delhi-NCR Using Satellite Data, Journal of Global Resources, Vol. 07 (02)

DOI:

10.46587/JGR.2021.v07i02.003

Received: 21 March 2021

Reviewed: 10 April 2021

Revised: 26 April 2021

Final Accepted: 23 May 2021

\begin{abstract}
This paper provides a comparative analysis of land use and land cover (LULC) changes among the study area of two decades (1999-2019). Landsat images (i.e., Landsat-5 and Landsat-8) acquired during the years of 1999, 2009, and 2019 were used to examine LULC changes in Delhi-NCR. A classification composed of five classes- i.e., Crop Land, Barren Land, Forest, Water, and Built-up were design for this study. This research indicates the necessity to implement change detection at multiple scales for better understanding the mechanism of LULC change patterns. The result indicates that the significant changes in LULC have occurred over time, with a rise in built-up, water, and cropland, and a decrease in forest and barren land. Built-up area has increased by 89.29 percent and water by 29.34 percent and crop land by 1.85 percent, while the forest and barren land have decreased by 81.51 and -9.02 percent respectively.
\end{abstract}

Keywords: Satellite Imagery, Land Use and Land Cover, Change Pattern, Delhi-NCR
OPEN O ACESS

Freely available Online www.isdesr.org 


\section{Introduction}

Due to India's rapid population and economic growth, land use and management practices are rapidly evolving, having a significant effect on the urban environment (Wilken et al., 2017). Urbanization is causing massive changes in land cover (Singh, 1998; Prasad \& Singh, 2018), which effects the surface's sensible and latent heat fluxes. In comparison to vegetative areas, concrete impervious surface areas have higher sensible heat, resulting in higher temperatures of urban built-up surfaces (Hang \& Rahman, 2018). It has been described as one of the most visible manifestations of human alteration of the earth, and as a result, it has become a key component of global environmental studies (Stemn \& Agyapong, 2014; Higgins, 2019). Rapid urbanization, driven by population and economic development, places additional demands on natural resources, resulting in land use changes (Singh \& Kumar, 2012; Liaqat et al., 2021; Zerga et al., 2021; Wang et al., 2021), especially in megacities (Mohan et al., 2011). Rapid urbanization results in unplanned and disorganised development of towns and cities, and it may be the most strong and noticeable anthropogenic force responsible for profound changes in land cover and landscape pattern around the world (Das \& Das 2017; Nishit, Pandey, Anand and Kumar, 2021; Pandey, Mishra and Pathak, 2020).

The LULC monitoring in rapidly urbanizing environments using remote sensing and GIS for quantifying and analysing urban landscape change dynamics and managing healthy urban ecosystems (Mugiraneza, Ban \& Haas, 2019). It is critical to reveal the temporal and spatial shifts in built-up land expansion and population growth in order to ensure the city's longterm viability (Luo et al., 2018). The key cause of LULC changes is the transfer of other forms of land to uses related to population development and economic activities. As a result, LULC are complex in nature and must be controlled on a regular basis to ensure long-term development. So, land use refers to how humans use the land and its resources, such as agriculture, grazing, logging, etc. (Mukherjee et al., 2009). LULC adjustment has become a critical component of emerging natural resource management and environment and environmental monitoring strategies (Pandey, 2005; Pandey, Prasad, Mishra, \& Godara, 2017; Kaul \& Sopan, 2012; Wang, Munkhnasan, \& Lee, 2021; Rasool, Fayaz, ul Shafiq, Singh, \& Ahmed, 2021).

Geospatial technology is critical for spatial and temporal monitoring of land use and land cover change (Kafy et al., 2021; Tadese, Kumar, Koech, \& Kogo, 2020), as well as developing a relationship between land use and land cover change and their effect on the urban environment over time, which is crucial for environmental management (Chaudhuri, Singh \& Rai, 2018). Remote sensing and GIS techniques have emerged as new methods for monitoring land use changes (Goyal, Sharma \& Singh, 2019). By characterising and quantifying changes in land use and land cover, remote sensing technology is one validated technique for better documenting and understanding urbanization (Wentz et al., 2008). Monitoring and quantifying urban development aids decision-making for the avoidance of negative environmental and socio-economic effects (Sapena \& Ruiz, 2019). Advances in remote sensing have provided useful tools to effectively track and examine complex changes in land use and land cover changes (Chaudhuri \& Mishra, 2016). Landsat 4 and 5 (TM) have a spatial resolution of $120 \mathrm{~m}$, while Landsat $7(\mathrm{ETM}+)$ has a finer resolution thermal data $(60$ m) (Hazaymeh \& Hassan, 2015). The Landsat-8 satellite $(30 \mathrm{~m})$ has two sensor payloads: The Operational Land Image (OLI) and the Thermal Infrared Sensor (TIRS) (Roy et al., 2014).

The key goal of the NCR was to relieve congestion in Delhi by redistributing population pressure to ring towns. Therefore, the NCR come into existence in 1985, when some surrounding districts of neighbouring states become part of it (Saroj, Sharma \& Prawasi, 2015). 
The NCR is characterized by a surge of physical and economic growth of Delhi and underdevelopment of the area outside it. This has been changing the land use and land cover of the NCR with profound regional environmental implications and a concomitant de-stabilization of the rural economy and food demand of the region, as evident from a range of localized studies across many agricultural areas within (Suzanchi \& Kaur, 2011; NCRPB, 2020).

\section{Study Area}

The National Capital Region (NCR) is located between $27.60^{\circ} \mathrm{N}$ to $29.30^{\circ} \mathrm{N}$ and $76.20^{\circ} \mathrm{E}$ to $78.40^{\circ} \mathrm{E}$ with a population density about 800 people per square kilometre, and spans four states: Delhi, Haryana, Rajasthan and Uttar Pradesh with a total 23 districts (NCRPB, 2020). The NCR covered a total area of $58,332 \mathrm{~km}^{2}$ during the study period, with Haryana occupying the largest portion $\left(28,545 \mathrm{~km}^{2}\right)$, followed by Uttar Pradesh $\left(14,826 \mathrm{~km}^{2}\right)$, Rajasthan $(13,447$ $\mathrm{km}^{2}$ ) and Delhi (1483 km²), (NCRPB, 2020) (Figure 1).

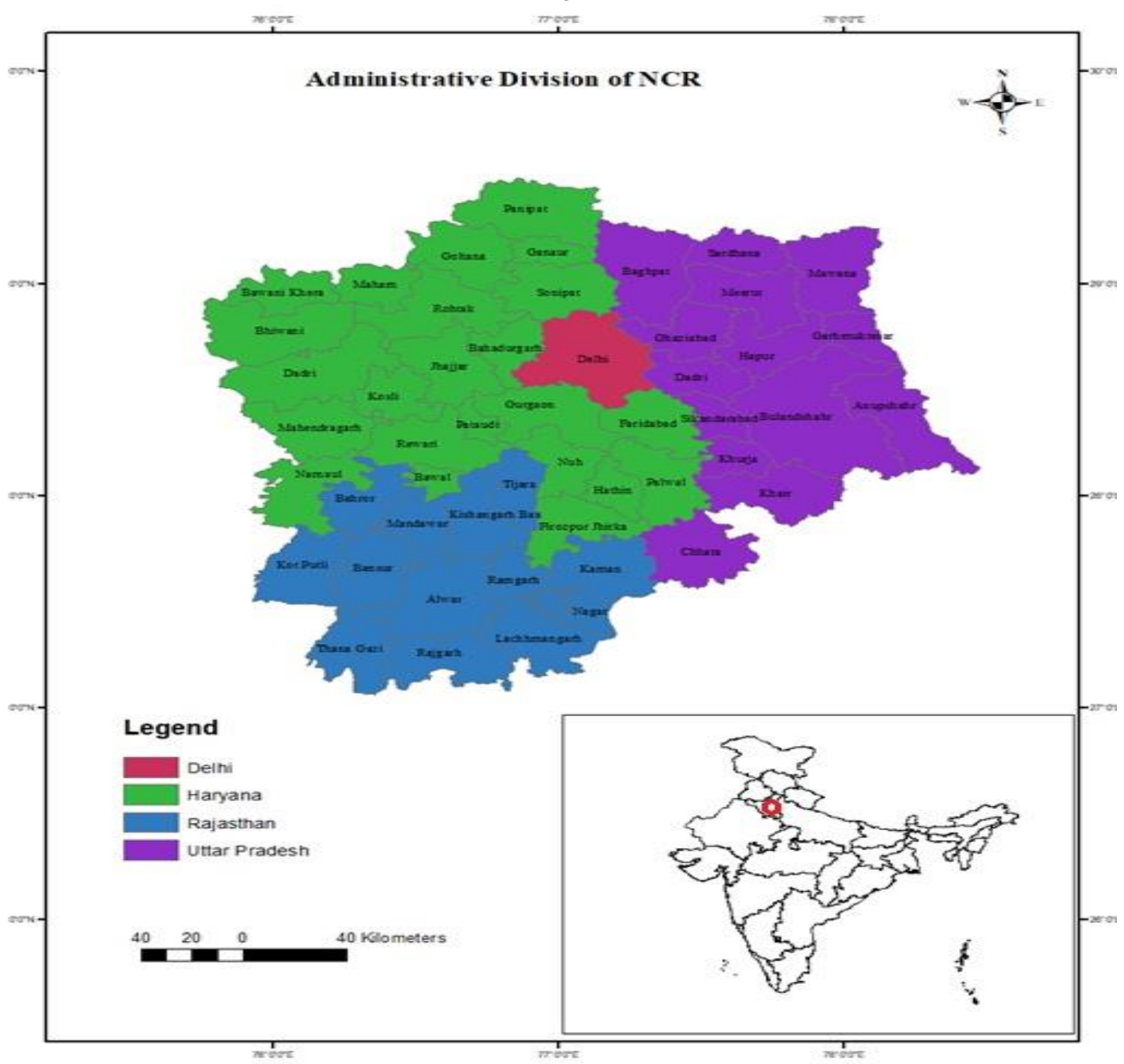

Figure 01: Location of the Study Area

(Source: Prepared by authors, 2020; NCRPB, 2020)

\section{Objective}

The primary goal is to determine the spatial-temporal patterns of land use/cover change over the last two decades (i.e., 1999 - 2019). 


\section{Sources and Methods}

Landsat- 5 and Landsat-8 satellite data derived from the United States Geological Survey (http://globis.usgs.gov) for three periods were used. The flow diagram depicts the technique used to detect changes in land use and land cover in the figure 2.

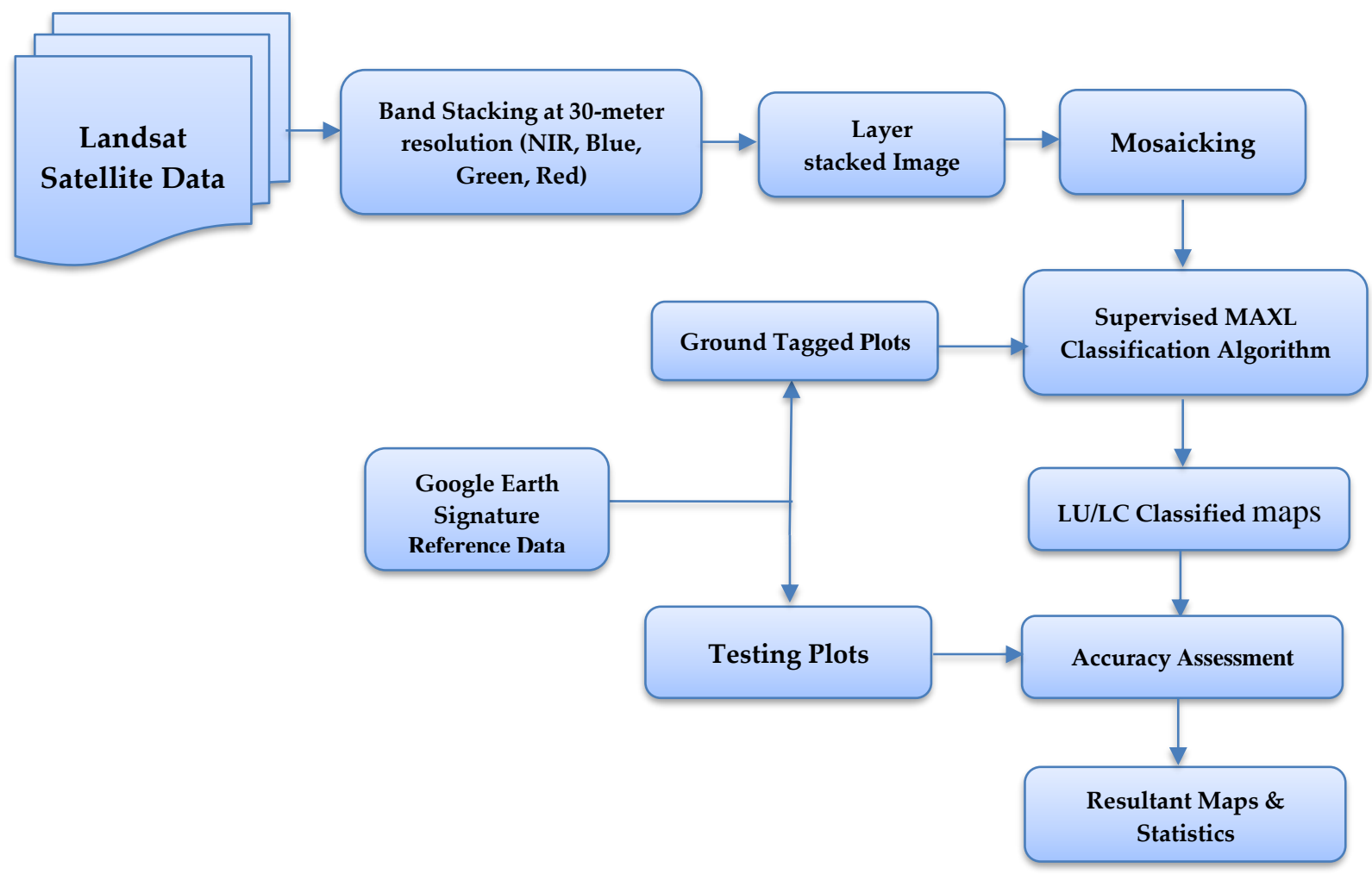

Figure 02: Methodology Framework

(Source: Prepared by Authors, 2020)

For this analysis, a maximum likelihood classifier has been used (Maselli, Conese, Petkov, \& Resti, 1992), which determines the probability that a given pixel belongs to a particular class based on the assuming that the statistics for each class in each band are normally distributed. The class with the highest probability is allocated to each pixel (that is, the maximum likelihood) (Paola, \& Schowengerdt, 1995). The Erdas accuracy assessment tool is used for validation and accuracy assessment, which creates random points on the classified image with the aid of classified classes and reference classes, and assigns values. After that, an error matrix is created to verify overall accuracy, and the kappa coefficient is determined which represents the proportionate reduction in error caused by a classification system relative to random classification. The overall accuracy is determined by multiplying the number of correctly classified values by the total number of values. The correctly categorised values are found on the uncertainty matrix's upper-left to lower-right diagonal. The total number of values in either the truth or predicted-value arrays is the total number of values. The kappa coefficient is a calculation of how well classification and truth value agree. Perfect agreement is represented by a kappa value of 1 , while no agreement is represented by a kappa value of 0 . The kappa coefficient is computed as follows:

$$
\kappa=\frac{N \sum_{i=1}^{n} m_{i, i}-\sum_{i=1}^{n}\left(G_{i} C_{i}\right)}{N^{2}-\sum_{i=1}^{n}\left(G_{i} C_{i}\right)}
$$


Where:

- $\mathbf{i}$ is the class number

- $\quad \mathbf{N}$ is the total number of classified values compared to truth values

- $\mathbf{m}_{\mathrm{i}, \mathrm{i}}$ is the number of values belonging to the truth class $\mathbf{i}$ that have also been classified as class $\mathbf{i}$ (i.e., values found along the diagonal of the confusion matrix)

- $\quad \mathbf{C}_{\mathbf{i}}$ is the total number of predicted values belonging to class $\mathbf{i}$

- $\mathbf{G}_{\mathbf{i}}$ is the total number of truth values belonging to class $\mathbf{i}$

\section{RESULT AND DISCUSSIONS}

\section{Land Use/ Cover Classification and Change Detection Accuracy}

Overall accuracies for season-classified images of land use and land cover for the years 1999 and 2019 were 92.00 percent and 90.00 percent respectively, with kappa statistics of 90.00 percent. Though overall accuracy for 2009 was 88.00 percent with kappa statistics 85.00 percent, overall accuracy for 2019 was 86 percent with kappa statistics 82.50 percent. The classification of images was performed with great care, but the classified images revealed some inconsistency between built-up and open space (This is due to the fact that reflectance value are similar). Repeated classifications with more ground truths/training sites did not enhance classification accuracy. We increased the number of classes for built-up and barren land, but mixing was observed due to similar reflectance. After applying the "haze reduction" filter to the consolidated data, the two sections were classified separately using the above mentioned "ordered clustering" method. The two independently classified sections were then mosaicked to create a single season (haze-free) classified image with enhanced overall accuracy and kappa statistics. A comparison of classified satellite image-based gross and net shown area estimates with corresponding estimates from independent ground-based land use inventories was used to assess the accuracy of satellite-based land use inventories. The results of this study, which included the base (1999) and most recent (2019) years, revealed that the discrepancies between the satellites were important.

\section{Land Use /Land Cover Change Statistics}

Despite the fact that land use/land cover classification maps were created for all three years, it is found that increasing the number of classes for the training site improves the overall accuracy of LULC classified maps, individual class area, and land use/land cover and change statistics for season classified table 1 and figure 3 summarise these numbers, respectively (Figure 4-6).

Table 01: Summary of Land Use/ Land Cover Classification Area Statistics for 1999, $2009 \& 2019$

\begin{tabular}{|c|c|c|c|c|c|c|c|}
\hline $\begin{array}{l}\text { Land Use } \\
\text { Classes }\end{array}$ & $\begin{array}{l}1999 \\
\text { Area } \\
\left(\mathrm{km}^{2}\right)\end{array}$ & Percent & $\begin{array}{l}2009 \\
\text { Area } \\
\left(\mathrm{km}^{2}\right)\end{array}$ & Percent & $\begin{array}{l}2019 \text { Area } \\
\left(\mathrm{km}^{2}\right)\end{array}$ & Percent & $\begin{array}{c}\text { Relative Change } \\
\text { Percentage (2019- } \\
\text { 1999) }\end{array}$ \\
\hline $\begin{array}{l}\text { Crop } \\
\text { Land }\end{array}$ & 28289.33 & 64.83 & 30931.01 & 70.88 & 28812.42 & 66.03 & 1.85 \\
\hline $\begin{array}{l}\text { Barren } \\
\text { Land }\end{array}$ & 11446.94 & 26.23 & 8568.09 & 19.64 & 10413.88 & 23.87 & -9.02 \\
\hline Forest & 1680.03 & 3.85 & 535.95 & 1.23 & 310.62 & 0.71 & -81.51 \\
\hline Water & 171.55 & 0.39 & 110.85 & 0.25 & 221.88 & 0.51 & 29.34 \\
\hline Built up & 2048.35 & 4.69 & 3490.3 & 8.00 & 3877.4 & 8.89 & 89.29 \\
\hline
\end{tabular}




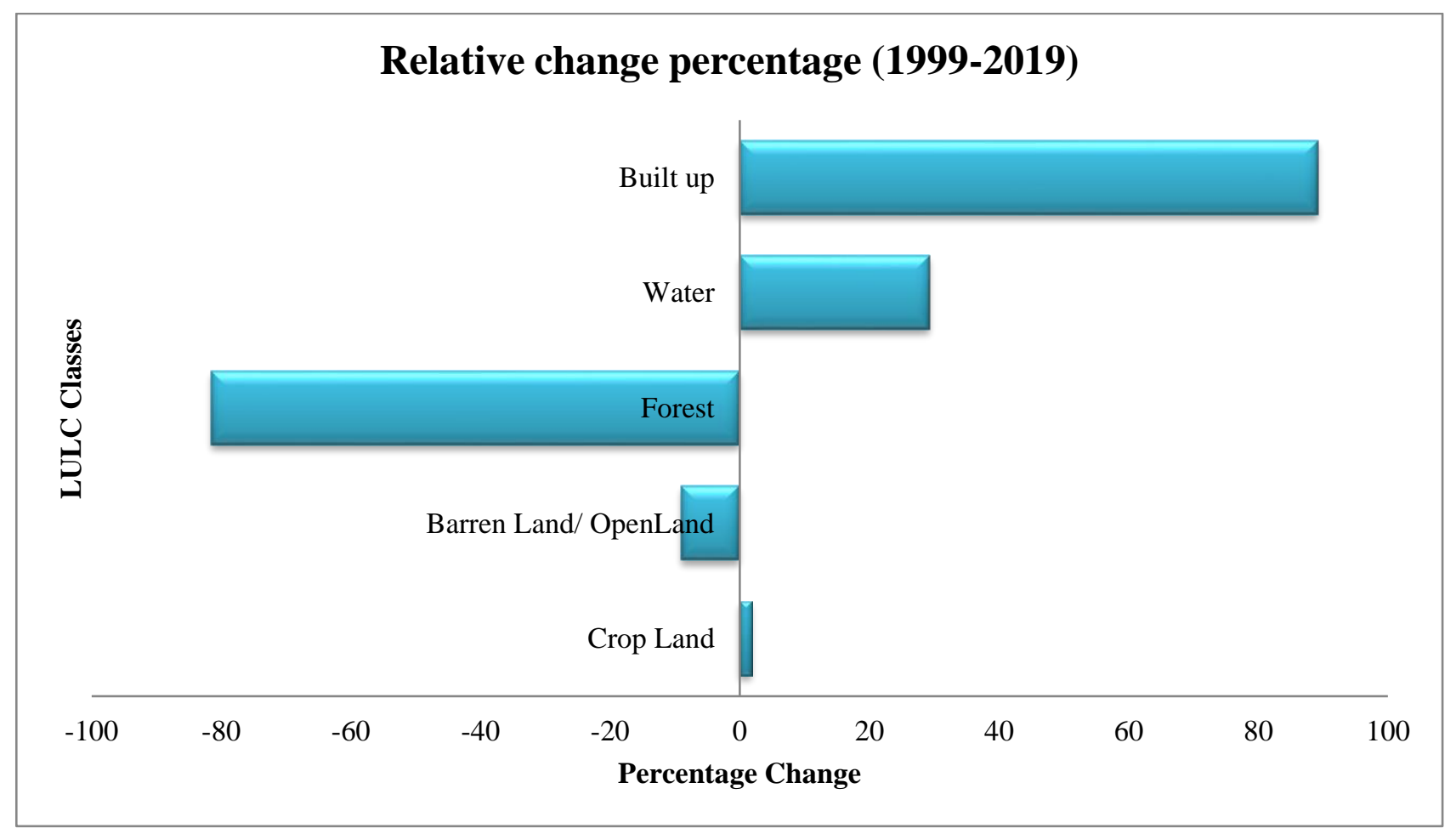

Figure 03: Relative percentage change of LU/LC (1999-2019)

(Source: Prepared by Authors, 2020)

\section{Suggestions and Recommendations}

1. It's important note that the forest area is declining, which is a major cause of pollution control concern. Consequently, it is expected that the value of agricultural land converted to built-up land will increase during the urban development process, making it suitable for urban development.

2. Land use/cover planning, as well as strategic regional planning in general, are critical tools for directing long-term urban and environmental development. Land regeneration, despite this, is a very elegant and economically viable choice for urban growth and redevelopment.

3. Land redevelopment would help to balance the benefits and disadvantages of urban planning.

4. In order to achieve sustainability, industrial growth is economically advantage, the development of spatial data infrastructure is needed, which will play a critical role in the decision-making process for the spread of economic activities and the spatial expansion of urban centres necessary for the environment's and urban development's long-term sustainability.

5. Appropriate governmental policies are needed for the construction of basic infrastructure 

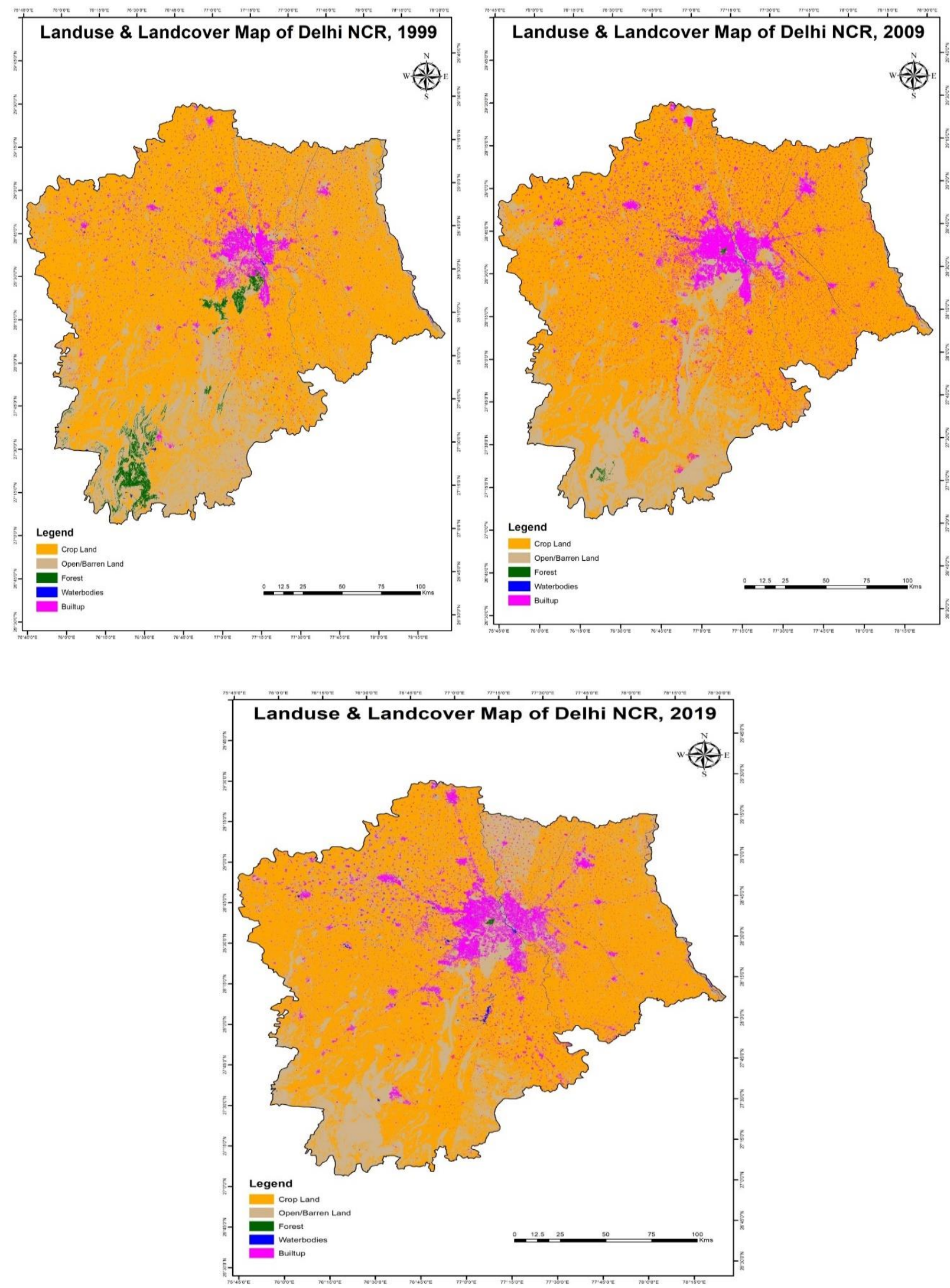

Figure 4-6: LU/LC pattern of Delhi-NCR

(Source: Prepared by Authors, 2020)

\section{Conclusion}

It is clearly showing that between 1999 and 2009, croplands increased by 6.82 percent, while barren land and water decreased by 6.76 percent and 2.33 percent, respectively. Matrixes of land cover adjustments from 1999 to 2019 were also produced to help assess the effects of 
land cover conversions. The major rise was 89.29 percent in built-up areas, owing to a 52.2 percent increase in urban population between 1989 and 1998. It's worth noting that, in contrast to previous years where the rural population was lower than the urban population, between 1991 and 2001, the urban population was around 29.3 percent higher than the rural population. Conversion of 8.9 percent of desert lands, 5.5 percent of ridge and forest lands, and 3.8 percent of croplands led to the overall increase 26.81 percent in built-up land.

Acknowledgements: The lead author is thankful to University Grant Commission (UGC) for providing funding. The authors also acknowledge to National Institute for the Humanities (HINDAS, University of Hiroshima, Japan). The authors also grateful to the all reviewers for their valuable suggestions, which lead to significant improvement of the Manuscript.

Conflicts of Interest: The authors declare that there is no financial or other conflict of interest.

\section{References}

1. Chaudhuri, A. S., Singh, P., and Rai, S. C. (2018). Modelling LULC change dynamics and its impact on environment and water security: geospatial technology-based assessment. Ecology, Environment and Conservation, 24, S292-S298.

2. Chaudhuri, G., and Mishra, N. B. (2016). Spatio-temporal dynamics of land cover and land surface temperature in Ganges-Brahmaputra delta: A comparative analysis between India and Bangladesh. Applied Geography, 68, 68-83.

3. Das, R., and Das (2017). G. ARS-GIS based Spatial Analysis and Assessment on the Urban Growth of Delhi National Capital Territory (NCT) from 1977 to 2014.

4. Goyal, A., Sharma M., and Singh D. D. (2019). Land Use/Land Cover Change Detection using Geoinformatics in Gurugram District, Haryana, India, International Journal of Recent Technology and Engineering, 8, 3735.

5. Hang, H. T., and Rahman, A. (2018). Characterization of thermal environment over heterogeneous surface of National Capital Region (NCR), India using LANDSAT-8 sensor for regional planning studies. Urban climate, 24, 1-18.

6. Hazaymeh, K., and Hassan, Q. K. (2015). Spatiotemporal image-fusion model for enhancing the temporal resolution of Landsat-8 surface reflectance images using MODIS images. Journal of Applied Remote Sensing, 9(1), 096095.

7. Higgins, C. D. (2019). A 4D spatio-temporal approach to modelling land value uplift from rapid transit in high density and topographically-rich cities. Landscape and urban planning, 185, 68-82.

8. Kafy, A. A., Shuvo, R. M., Naim, M. N. H., Sikdar, M. S., Chowdhury, R. R., Islam, M. A., \& Kona, M. A. (2021). Remote sensing approach to simulate the land use/land cover and seasonal land surface temperature change using machine learning algorithms in a fastest-growing megacity of Bangladesh. Remote Sensing Applications: Society and Environment, 21, 100463.

9. Liaqat, M. U., Mohamed, M. M., Chowdhury, R., Elmahdy, S. I., Khan, Q., \& Ansari, R. (2021). Impact of Land Use/Land Cover Changes on Ground Water Resources in Al Ain Region of the United Arab Emirates Using Remote Sensing and GIS Techniques. Groundwater for Sustainable Development, 100587.

10. Luo, J., Xing, X., Wu, Y., Zhang, W., and Chen, R. S. (2018). Spatio-temporal analysis on built-up land expansion and population growth in the Yangtze River Delta Region, China: From a coordination perspective. Applied Geography, 96, 98-108.

11. Maselli, F., Conese, C., Petkov, L., \& Resti, R. (1992). Inclusion of prior probabilities derived from a nonparametric process into the maximum-likelihood classifier. Photogrammetric Engineering and Remote Sensing, 58(2), 201-207.

12. Mohan, M., Pathan, S. K., Narendra Reddy, K., Kandya, A., and Pandey, S. (2011). Dynamics of urbanization and its impact on land-use/land-cover: a case study of megacity Delhi. Journal of Environmental Protection, 2(09), 1274.

13. Mugiraneza, T., Ban, Y., and Haas, J. (2019). Urban land cover dynamics and their impact on ecosystem services in Kigali, Rwanda using multi-temporal Landsat data. Remote Sensing Applications: Society and Environment, 13, 234-246.

14. Mukherjee, S., Shashtri, S., Singh, C. K., Srivastava, P. K., and Gupta, M. (2009). Effect of canal on land use/land cover using remote sensing and GIS. Journal of the Indian society of remote sensing, 37(3), 527-537.

15. NCRPB (2020). Evolution of the Concept of the National Capital Region. http://ncrpb.nic.in/history.html. 
16. Nishit, Pandey, B.W., Anand, S. and Kumar, H., (2021). Demographic Transformation, Land use Change and its Environmental Implications in Kotla -Mubarakpur, New Delhi. Indian Journal of Spatial Science, EISSN: 2249 - 4316, ISSN: 2249 - 3921, Spring Issue 2021, (1) Pp. 29-38.

17. Pandey, B. W., Mishra, H., and Usha Kumari Pathak (2020). Planning for Healthy and Sustainable Urbanization: A Case Study of National Capital Territory, Delhi V. R. Sharma and Chandrakanta (eds.), Making Cities Resilient, The Urban Book Series, https://doi.org/10.1007/978-3-319-949321_5, ISSN 2365-757X ISSN 2365-7588 (electronic) The Urban Book Series ISBN 978-3-319-949314 ISBN 978-3-319-94932-1 (eBook) Springer Nature Switzerland AG 2019 (C) Springer Nature Singapore Pte Ltd.

18. Pandey, B.W. (2005). Comparative analysis of land use land cover changes in the headwater region of Beas, the western Himalaya. Natural Resource Management, 195.

19. Pandey, B.W., Prasad, A. S., Mishra, H., \& Godara, S. (2017). Urban Dynamics and Resource Consumption: A Case Study of NCT of Delhi. In Sustainable Smart Cities in India (pp. 333-351). Springer, Cham.

20. Paola, J. D., \& Schowengerdt, R. A. (1995). A detailed comparison of backpropagation neural network and maximum-likelihood classifiers for urban land use classification. IEEE Transactions on Geoscience and remote sensing, 33(4), 981-996.

21. Prasad, S., \& Singh, R. B. (2018). Urbanization and Land use/Land Cover Change in Varanasi City. National Geographical Journal of India, 64(1-2), 185-197.

22. Rasool, R., Fayaz, A., ul Shafiq, M., Singh, H., \& Ahmed, P. (2021). Land use land cover change in Kashmir Himalaya: Linking remote sensing with an indicator based DPSIR approach. Ecological Indicators, 125, 107447.

23. Roy, D. P., Wulder, M. A., Loveland, T. R., Woodcock, C. E., Allen, R. G., Anderson, M. C., and Scambos, T. A. (2014). Landsat-8: Science and product vision for terrestrial global change research. Remote sensing of Environment, 145, 154-172.

24. Sapena, M., and Ruiz, L. Á. (2019). Analysis of land use/land cover spatio-temporal metrics and population dynamics for urban growth characterization. Computers, Environment and Urban Systems, 73, 27-39.

25. Saroj, Sharma M.P., Prawasi R. (2015). Land Use /Land Cover Change Detection Using Remote Sensing and Gis in Rohtak and Jhajjar Districts of Ncr, Haryana, India. International Journal of Science, Engineering and Technology Research, 4, 1.

26. Singh, R. B. (1998) "Land use/cover changes, extreme events and ecohydrological responses in the Himalayan region." Hydrological Processes 12, no. 13-14: 2043-2055.

27. Singh, R. B., \& Kumar, D. (2012). Remote sensing and GIS for land use/cover mapping and integrated land management: case from the middle Ganga plain. Frontiers of Earth Science, 6(2), 167-176.

28. Stemn, E., and Agyapong, E. (2014). Assessment of urban expansion in the Sekondi-Takoradi Metropolis of Ghana using remote-sensing and GIS approach. International Journal of Science and Technology, 3(8), 452-460.

29. Suzanchi, K., and Kaur, R. (2011). Land use land cover change in National Capital Region of India: a remote sensing and GIS based two decadal spatial-temporal analyses. Procedia-Social and Behavioural Sciences, 21, 212-221.

30. Tadese, M., Kumar, L., Koech, R., \& Kogo, B. K. (2020). Mapping of land-use/land-cover changes and its dynamics in Awash River Basin using remote sensing and GIS. Remote Sensing Applications: Society and Environment, 19, 100352.

31. Wang, H., Liu, X., Zhao, C., Chang, Y., Liu, Y., \& Zang, F. (2021). Spatial-temporal pattern analysis of landscape ecological risk assessment based on land use/land cover change in Baishuijiang National nature reserve in Gansu Province, China. Ecological Indicators, 124, 107454.

32. Wang, S. W., Munkhnasan, L., \& Lee, W. K. (2021). Land use and land cover change detection and prediction in Bhutan's high-altitude city of Thimphu, using cellular automata and Markov chain. Environmental Challenges, 2, 100017.

33. Wentz, E. A., Nelson, D., Rahman, A., Stefanov, W. L., and Roy, S. S. (2008). Expert system classification of urban land use/cover for Delhi, India. International Journal of Remote Sensing, 29(15), 4405-4427.

34. Wilken, F., Wagner, P. D., Narasimhan, B., and Fiener, P. (2017). Spatio-temporal patterns of land use and cropping frequency in a tropical catchment of South India. Applied Geography, 89, 124132.

35. Zerga, B., Warkineh, B., Teketay, D., Woldetsadik, M., \& Sahle, M. (2021). Land Use and Land Cover Changes Driven by Expansion of Eucalypt Plantations in the Western Gurage Watersheds, Central-south Ethiopia. Trees, Forests and People, 100087. 